\title{
Review Pengaruh Local Strongman Di Provinsi Jambi (Studi Kasus Dominasi Zulkifli Nurdin Terhadap Partai Amanat Nasional) \\ Oleh:
}

\author{
${ }^{1}$ Zakly Hanafi Ahmad, ${ }^{2}$ Aryo Akbar, ${ }^{3}$ Adlin \\ ${ }^{1}$ Mahasiswa Jurusan Ilmu Pemerintahan, Fakultas Ilmu Sosial Ilmu Politik, \\ Universitas Riau \\ ${ }^{2}$ Program Studi Ilmu Hukum Fakultas Hukum, Universitas Islam Riau \\ ${ }^{3}$ Jurusan Ilmu Pemerintahan, Fakultas Ilmu Sosial Ilmu Politik, Universitas Riau \\ 1zaklyhanafi@gmail.com, ${ }^{2}$ aryoakbar@law.uir.ac.id, adlin@lecturer.unri.ac.id
}

\begin{abstract}
ABSTRAK
Peralihan kekuasaan dari sentralisasi menuju desentralisasi telah banyak mempengaruhi iklim politik setiap daerah di Indonesia, hadirnya orang kuat lokal merupakan hal yang sedang mewabah di negara demokrasi. Dinamika yang terjadi mengakibatkan adanya dominasi ekonomi dan politik yang berimbas pada kehidupan demokrasi. Penelitian ini menggunakan pendekatan studi literatur dengan teknik pengumpulan data yang berasal dari berita online, buku dan penelitian yang berkaitan dengan pembahasan. Penelitian ini memiliki tujuan untuk mengeksplorasi dan mendalami bagaimana Peran Zulkifli Nurdin dalam membuat polarisasi Partai Amanat Nasional di Provinsi Jambi hingga mempertahankan citranya sebagai orang kuat lokal. Dominasi Zulkifli Nurdin berhasil membuat Partai Amanat Nasional sebagai alat untuk membentuk dinasti politiknya di Jambi, hal ini terbutki dari petinggi di Partai Amanat Nasional hanya terdiri dari keluarga dan kroni-kroninya saja.
\end{abstract}

Kata Kunci : peran, dominasi, local strongman

\begin{abstract}
ABSTRACK
The transfer of power from centralization to decentralization has greatly influenced the political climate of every region in Indonesia, the presence of local strongmen is an epidemic in a democratic country. The dynamics that occur have resulted in economic and political domination which has an impact on democratic life. This study uses a literature study approach with data collection techniques derived from online news, books and research related to the discussion. This research aims to explore and explore how the role of Zulkifli Nurdin in polarizing the National Mandate Party in Jambi Province to maintain its image as a local strongman. Zulkifli Nurdin's domination succeeded in making the National Mandate Party as a tool to form his political dynasty in Jambi, this was made up of officials in the National Mandate Party consisting only of his family and cronies.
\end{abstract}

Keywords: role, domination, local strongman 


\section{REVIEW PENGARUH LOCAL STRONGMAN DI PROVINSI JAMBI (STUDI KASUS DOMINASI ZULKIFLI NURDIN TERHADAP PARTAI AMANAT NASIONAL)}

\section{PENDAHULUAN}

Pasca lengsernya Soeharto dan berakhirnya rezim otoritarian Orde Baru, semangat dan gairah berdemokrasi masyarakat tumbuh di mana-mana. Situasi yang telah mengubah sistem politik dan melahirkan reformasi ini memberi peluang bagi berlangsungnya demokratisasi di Indonesia. Dalam konteks cakupan aktor penyelenggara kekuasaan terjadi perubahan signifikan yang mana aktor-aktor yang terlibat dalam proses kekuasaan semakin plural. Secara vertikal, perubahan kekuasaan menunjukkan bahwa politik tidak lagi didominasi pemerintah pusat. Transisi dari rezim nondemokratik yang sentralistik menuju pemerintahan dan kehidupan desentralisasi yang sungguh-sungguh demokratis terbukti tidak mudah dilalui. Berbagai hambatan dan distorsi mewarnai kehidupan politik dan agenda konsolidasi demokrasi di Indonesia, salah satu hambatan problematis yang sekaligus merupakan distorsi dalam kerangka demokratisasi dan penataan kehidupan politik yang lebih baik itu adalah munculnya fenomena orang kuat lokal di berbagai daerah.

Politik lokal di Indonesia semakin dinamik setelah masa desentralisasi, ketika kekuatan masyarakat mulai merembes masuk ke lembaga-lembaga formal. Keadaan ini lebih kurang merupakan legasi positif dari hadirnya reformasi yang menyediakan kesempatan kepada masyarakat awam agar bisa terlibat dalam partisipasi politik. Masyarakat lokal yang tadinya dibayang- bayang akan mampu bersaing ternyata tidak semulus yang dibayangkan, peran orang kuaat lokal dan para saudagar ternyata merubah pandangan itu semua, persaingan justru hanya bisa dilakukan oleh orang- orang yang mempunyai harta ataupun citra besar yang sudah ada sebelum reformasi hadir.

Berbagai macam organisasi informal di luar Negara seperti etnisitas, golongan bahkan kelompok-kelompok semacam sekte agama adalah berbagai kekuatan yang bisa saja menganggu bahkan menghalangi jalannya berbagai macam norma pembangunan yang telah ditetapkan oleh negara, hal ini banyak ditemukan pada kasus di negaranegara dunia ketiga dalam hal ini negara baru merdeka, di negara-negara yang baru merdeka, modernisasi atauran hukum bisa jadi masih bertolak belakang dengan norma tradisional yang secara kultur masih kuat tertanam pada kehidupan masyarakat. Kasus ini lebih diperparah lagi dengan kompetensi antar kelompok kepentingan diantara 
mereka untuk mengambil alih kekuasaan yang diwariskan pasca kolonialisme yang dilakukan oleh penjajah, maka akan terlihat wajar saja bila kondisi di negara dunia ketiga terbilang lemah. Sebab infrastruktur negara baik yang berupa sumber daya manusia maupun dalam aspel penerapan hukum, masih dalam tahap perkembangan sehingga kontrol sosial sangat sulit di implementasikan (Agustino, 2016).

Analisis Migdal, berdasarkan kondisi realitas politik dengan munculnya kelompok- kelompok atau institusi informal di luar negara yang mengurangi efektivitas dan kapabilitas negara, di beberapa negara dunia ketiga menunjukkan bahwa, kelemahan-kelemahan negara dunia ketiga telah melahirkan orang-orang kuat di tingkat lokal. (Migdal, 2004) menyebut orang kuat lokal dengan sebutan local strongman. Orang kuat lokal di definisikan sebagai kekuatan informal yang berupa tuan tanah, saudgar, pengusaha kaya, kepala suku, panglima perang, bos petani kaya, pemimpin golongan, pemimpin sekte agama, tokoh adat dan lain sebagainya, yang berusaha menguasai kontrol atas masyarakat dalam cakupan wilayah tertentu lewat kerjasama jejaring yang mereka bangun. Ringkasnya, keberhasilan local strongman atau orang kuat lokal dalam mencapai monopoli dan kontrol sosial mereka di masyarakat menurut (Migdal, 2004) didasari atas tiga faktor utama.

1. Pertama, karena sifat masyarakat yang berbentuk jejaring, dimana klientilisme tumbuh subur dan berkembang. Sehingga kontrol sosial terfokus pada kekuatan- kekuatan yang ada, karena tidak mampu dimonopoli oleh negara.

2. Kedua, karena mindset yang mendarah daging yang ada dalam diri orang kuat lokal di masyarakat, dan sudah menjadi simbol tersendiri di antara mereka, yang mana orang kuat menjadi panutan dikehidupan masyarakat lokal.

3. Ketiga, kemampuan orang kuat lokal mengintervensi lembaga yang ada di daerah sehingga menjadikan alur lembaga pemerintahan disana berpihak kepada kepentingan mereka.

Melalui proses demokratisasi dan desentralisasi, para local strongmen dan bos ekonomi semakin memperoleh kesempatan untuk menjabat kursi sentral di lembagalembaga pemerintahan daerah dibandingkan masa-masa sebelumnya. Kalaupun mereka tidak memangku jabatan-jabatan penting tersebut, para orang kuat lokal ini selalu 
berupaya untuk memastikan bahwa para politisi dan birokrat lokal bergantung pada bantuan dan dukungannya agar kebijakan resmi menguntungkan bisnis dan posisinya (Apriyani, 2020).

Pengertian bos lokal dalam penelitian (Holifah, 2012) merujuk kepada broker lokal yang menikmati posisi monopolistik atas cara kekerasan dan sumber ekonomi dalam wilayah kekuasaan mereka masing-masing, seperti posisi walikota/bupati yang menjalankan daerahnya layaknya kekuasaan pribadi mereka sendiri, atau kalangan dewan dan gubernur yang membangun mesin politik dan kerajaan bisnis yang merentang di seluruh distrik atau provinsi. Bos lokal ini hadir dengan mekanisme pemilu yang kompetitif dan berkala serta diikuti partisipasi politik yang tinggi. Mereka menggunakan berbagai strategi dari pembelian suara, manipulasi hingga intimidasi dengan penggunaan kekerasan ataupun uang. Bosisme beroperasi dalam bayangan rezim otonomi daerah yang dicirikan oleh persekutuan birokrat, bos-bos partai, pengusaha, militer, dan preman. Para "bossism local" menggunakan aparatur negara untuk menggerakkan masyarakat agar mengikuti kehendaknya.

Bossism local ada di setiap tingkatan, ada bos yang menguasai wilayah pada (kabupaten/kota), ada bos yang menguasai provinsi dan ada bos yang menguasai pusat. Jejaring patron-klien para "bossism local"” tidak statis dan permanen, melainkan dinamis dan sangat cair. Mereka bisa berpindah-pindah patron di tingkat pusat, berpindah-pindah klien di tingkat lokal dan berpindah-pindah afiliasi parta politik nasional. Bosisme Lokal melakukan transaksional suara pemilih dengan bantuan ekonomi (berbentuk uang tunai), sembako, bibit, irigasi, pelunasan hutang dan alat tukar lainnya. Mereka sangat mengerti dengan memberikan bantuan kesehatan, memberikan bantuan pekerjaan, memberikan bantuan hukum, maka kemudian ketika hari $\mathrm{H}$ pemilihan umum, mereka mengubah bantuan-bantuan yang mereka berikan menjadi suara dan dukungan politik.

Berbagai strategi dilakukan bossism local untuk mempertahankan dominasinya dalam bida ekonomi dan politik. Strategi tersebut diantaranya:

(1) Menempatkan keluarga dan kroni sebagai walikota/bupati, wakil dan anggota dewan perwakilan rakyat daerah

(2) Mengatur penempatan posisi pejabat daerah

(3) Mengatur alur dan pilihan proyek pembangunan pemerintah

(4) Mengatur pembentukan peraturan daerah 
(5) Mengatur keringanan pajak

(6) Mengatur pinjaman dari Bank Pembangunan Daerah

(7) Memberikan konsesi dan kontrak pertambangan, kehutanan dan perkebunan

(8) Intimidasi dan kekerasan politik

(9) Menerapkan kebijakan diskriminatif untuk mengatasi konflik tanah dan melemahkan serikat buruh

Fenomena bossism local yang mempertahankan relasi sisa feodalisme di zaman kapitalisme dan demokrasi muncul akibat dari kebutuhan ekonomi yang konkrit dan langsung dibutuhkan, ketimpangan sosial yang sangat tinggi dan kelangkaan akses terhadap barang kebutuhan pokok. Menurut (Sidel, 2000) orang-orang kuat lokal local strongmen yang menguasai lembaga-lembaga demokrasi seperti partai politik, parlemen dan pemilihan umum ketika terjadi desentralisasi dan demokratisasi pasca pemerintahan orde baru. Orang kuat lokal dihambat kemunculannya selama Orde Baru dan dihambat juga ketika sistem pemilihan tidak langsung. Namun, apabila dilakukan perubahan sistem pemilihan menjadi pemilihan langsung maka local strongman dapat muncul dan berkembang di Indonesia.

Reformasi melahirkan posko kekuasaan baru di tingkat pusat maupun daerah, seperti partai politik baru dan penyelenggara pemerintah daerah (desentralisasi). Lahirnya partai politik secara otomatis melahirkan ketua partai politik baru di tingkat pusat dan daerah. Desentralisasi yang memberikan kewenangan yang luas kepada Gubernur, Bupati dan Walikota untuk mengatur daerahnya sendiri. Desentralisasi mendorong lahirnya pemimpin daerah melalui rekruitmen politik secara inklusif. Namun demikian, pemberian desentralisasi tidak secara langsung melahirkan demokratisasi, justru kenyataan sebaliknya memunculkan praktek korupsi, kolusi, nepotisme, yang dahulu menjadi kebiasaan rezim masa lampau yang menjadi bagian dari rezim sentral Orde Baru, dan yang sekarang dibangun dilembagakan ke dalam polapola patrimonial yang sudah ada di tingkat daerah.

Fenomena local strongmen terlihat jelas di Provinsi Jambi, yang mana keluarga Zulkifli Nurdin beserta Partai Amanat Nasional yang dibesarkanya di sana merupakan cerminan nyata kiprah orang kuat lokal di Provinsi Jambi. Zulkifli Nurdin sebelum jadi Gubernur Jambi, memang sudah terkenal sedari kecil. Ia anak Nurdin Hamzah, seorang pengusaha legendaris yang tak hanya punya jaringan yang sangat luas. Namun, juga dihormati karena sikapnya yang pemurah. Di masa jayanya, ia kerapkali memberikan 
santunan kepada mereka yang tak mampu. Adapun, citra Nurdin sendiri menurun dengan baik pada anaknya Zulkifli. Di Jambi, ia turut serta dalam beberapa organisasi profesi semaca Kadin (Kamar Dagang dan Industri) Provinsi Jambi dan Gapensi (Gabungan Penguasaha Seluruh Indonesia) dan ia memiliki posisi yang strategis saat itu, di tengah kesibukannya sebagai pengusaha, ia masih rajin bersedekah dan datang ke kampung-kampung bertemu dengan masyarakat. Serta, ia juga sosok yang religius, tak jarang ia muncul di acara keagamaan. Kombinasi maut inilah yang menjadikan jalanya mulus ketika memutuskan untuk terjun kedunia politik pada tahun 1996, dari memasuki partai Golongan Karya hingga berpindah ke Partai Amanat Nasional ketika Reformasi dan langsung menjadi Ketua Dewan.

Pimpinan Daerah pertama nantinya turut membesarkan polarisasi partai ini disetiap daerah di Provinsi Jambi. Berlatar uraian tersebut diatas, fokus permasalahan dalam studi ini adalah bagaimana Peran Zulkifli Nurdin dalam membuat polarisasi Partai Amanat Nasional di Provinsi Jambi hingga mempertahankan citranya sebagai orang kuat lokal. Dengan demikian maka tujuan penelitian ini adalah untuk mengeksplorasi dan mendalami bagaimana Peran Zulkifli Nurdin dalam membuat polarisasi Partai Amanat Nasional di Provinsi Jambi hingga mempertahankan citranya sebagai orang kuat lokal.

\section{METODE PENELITIAN}

Pendekatan yang digunakan pada penelitian ini adalah dengan menggunakan pendekatan literature review Dalam melakukan pengumpulan data penulis mengumpulkan data dan informasi yang berkaitan dengan pengaruh Zulkifli Nurdin dalam dominasi PAN di Jambi, melalui data-data pendukung yang bersumber dari jurnal penelitian baik nasional maupun internasional, buku-buku penunjang, surat kabar, dan majalah. literature review seperti yang dalam (Creswell, 2010) memiliki beberapa tujuan yaitu menginformasikan kepada pembaca hasil-hasil penelitian lain yang berkaitan erat dengan penelitian yang dilakukan saat itu, menghubungkan penelitian dengan literatur yang ada, dan mengisi celah dalam penelitian-penelitian sebelumnya, literature review berisi ulasan, rangkuman, dan pemikiran penulis tentang beberapa sumber pustaka (artikel, slide, buku dan informasi dari internet, data gambar dan grafik dan lain-lain) tentang topik yang dibahas. Studi literatur ini memiliki tujuan untuk mengetahui pengaruh dan peran dari Zulkifli Nurdin dalam dominasinya pada Partai Amanat Nasional di Provinsi Jambi. Teknik pengumpulan data yaitu dokumentasi. 


\section{HASIL DAN PEMBAHASAN}

\section{Membangun Partai Amanat Nasional di Jambi}

Pembahasan tentang penelitian ini seperti yang disinggung diawal kisah tentang peran besar Zulkifli Nurdin dalam membangun polarisasi Partai Amanat Nasional yang baru berdiri saat reformasi sangat berpengaruh hingga saat ini. Kisah ini dimulai dari awal lahirnya Zulkifli Nurdin sang putera seorang saudagar dari Muara Sabak, beliau lahir pada tanggal 12 Juli 1948 di Muara Sabak saat agresi militer Belanda tengah terjadi, meskipun Zulkifli lahir di keluarga yang secara sosial dan ekonomi di atas rata-rata, Ia tak berlaku sombong atau berbesar hati, bahkan pada masa kecilnya Zulkifli turut membantu Ayahnya dalam berjualan tepung terigu bersama pekerja yang di upah ayahnya. Begitu juga untuk urusan sekolah, Zulkifli memilih lembaga pendidikan negeri milik pemerintah dari pada bersekolah di sekolah swasta elit, setelah menamatkan sekolahnya dia bekerja pada perusahaan orang tuanya, Zulkifli Nurdin tercatat pernah memegang jabatan sebagai wakil kepala cabang PT. Nurdin Hamzah di Jakarta, Kepala cabang PT. Nurdin Hamzah di Jakarta, Dirut PT. Nurdin Hamzah Jambi (Rachmawan, 2018).

Ditengah kesibukan nya sebagai pengusaha, ia masih rajin bersedekah dan datang ke kampung- kampung bertemu dengan masyarakat. Serta, ia juga merupakan sosok yang religius, tak jarang ia muncul dalam acara keagamaan. Kombinasi maut itu membuahkan sebuah ilusi di benak pikiran masyarakat Jambi kebanyakan. Zulkifli adalah Jambi dan Jambi adalah Zulkifli. Formula maut itu membuat jalannya mulus ketika ia memutuskan untuk terjun ke dunia politik pada 1996. Pada 1996, Zulkifli bergabung dengan Partai Golongan Karya (Golkar). Dan, kala ia bergabung, ia langsung diberi jabatan strategis. Ia langsung dinobatkan menjadi Bendahara Partai Golkar. Kemudian, pada 1998, saat reformasi terjadi dan saat peta politik dan ekonomi berubah drastis di Jambi, ia memilih pindah ke Partai Amanat Nasional (PAN).

Sejak bergabung di Partai Amanat Nasional, sama seperti di Golkar, ia langsung diberi jabatan strategis. Ia ditunjuk sebagai Dalam kepartaian dia juga menjabat sebagai ketua umum PAN Kota Jambi tahun 1998 sampai tahun 2001 dan selanjutnya sebagai Ketua Dewan Pimpinan Wilayah (PDW) PAN tahun 2001 sampai tahun 2004. Sebelum itu pada tahun 1999 Zulkifli mencalonkan diri sebagai Anggota DPR RI tahun 1999, 
dan terpilih. Sebelum pada akhirnya memilih langkah nekat untuk mencalonkan diri sebagai Gubernur Jambi di tahun yang sama. Akan tetapi, kenekatannya ini berbuah hasil yang positif baginya. Ia, dengan nama-nama seperti Hasip Kalimudin Syam dan Ramlie Jalil yang lebih mapan dan matang dalam pengalamannya berpolitik di Jambi sebagai saingan, berhasil menjadi pemenang. Pada 1999, ia dilantik menjadi Gubernur Jambi (Ketek, 2018).

Meski mulanya diragukan, namun pada akhirnya Zulkifli berhasil meyakinkan semua orang bahwa Jambi akan baik-baik saja di tangannya. Bahkan, Zulkifli berhasil membangun tim politik impian yang tidak punya lawannya. Mulai dari menguasai PAN, menarik aktivis gerakan 98 untuk menjadi staff pribadinya, merangkul hampir seluruh perwakilan etnis yang ada di Jambi, menempatkan sanak famili dan orang terdekatnya di jabatan strategis, hingga merangkul pers di Jambi, sehingga jangan heran, ketika pada 2005, Zulkifli kembali terpilih menjadi Gubernur Jambi dengan angka yang begitu mencolok. Ia menjadi gubernur dengan jumlah pemilih di Jambi dengan persentase di atas 70\%. Polarisasi PAN di Provinsi Jambi bisa dilihat dari munculnya kepala daerah Kabupaten/ Kota dan banyaknya anggota Dewan Perwakilan Rakyat Daerah yang berasal dari partai PAN, itu dikarenakan mendapat pengaruh nama baik Partai dari seorang Zulkifli Nurdin yang berhasil membangun citranya dengan baik.

\section{Modal Pembangunan Semasa Menjadi Gubernur}

Pertumbuhan ekonomi Jambi dibawah kepemimpinan Zulkifli Nurdin mengalami peningkatan., Pertumbuhan ekonomi Jambi selalu diatas $5 \%$. Pertumbuhan ekonomi Jambi yang terendah adalah $5 \%$ pada tahun 2003. Bahkan pada tahun 2008 dan tahun 2010 pertumbuhan ekonomi menembus 7 \%. Pertumbuhan ekonomi Jambi tahun 2008 mencapai 7,16 \%. Pertumbuhan ekonomi Jambi tahun 2010 mencapai 7,30 \%. Geliat perekonomian benar-benar terasa saat Zulkifli memimpin, antara lain infrastruktur jalan dan jembatan, transportasi udara dan laut, industri dan perdagangan, usaha ekonomi rakyat dan lingkungan hidup. Sewaktu akhir masa jabatannya tahun 2010, pembangunan Jembatan Batanghari II sepanjang 1.351 meter dan lebar sembilan meter dan jalan Kota Jambi - Muarasabak, Kabupaten Tanjungjabung Timur sekitar $61,8 \mathrm{Km}$ rampung. Jembaatan ini berhasil membuka isolasi daerah terisolir di pantai timur Jambi. 
Tabel 1.1. Pertumbuhan Ekonomi Provinsi Jambi Tahun 2001 - 2010.

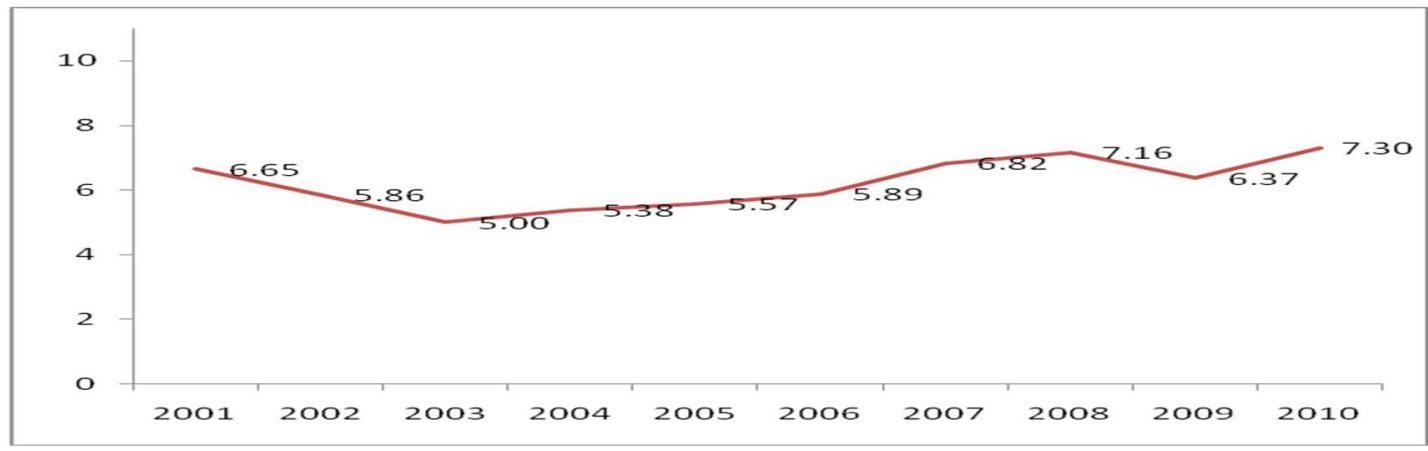

Sumber : (Melvin, Perjuangan, 2012)

Naluri bisnis Mantan Ketua Kamar Dangan dan Industri Indonesia (Kadin) Provinsi Jambi juga membuat Zulkifli Nurdin juga berhasil membangkitkan perekonomian, khususnya pedagangan. Semasa kepemimpinan Zulkifli, pusat perbelanjaan dan pertokoan banyak dibangun di Kota Jambi. Sebelumnya, pembangunan pusat perbelanjaan terkesan mandeg akibat sulitnya pengurusan izin investasi. Untuk meningkatkan minat investor, Zulkilfi Nurdin juga berhasil memantik peningkatan transportasi udara. Pada periode pertamanya (1999 - 2004), penerbangan Jakarta - Kota Jambi meningkat drastis dari dua - tiga jadwal penerbangan sehari menjadi 10 kali sehari. Maskapai penerbangan yang melayani penerbangan ke Jambi juga bertambah dari satu menjadi lebih lima maskapai. Zulkifli Nurdin juga sempat mengagas pembukaan penerbangan internasional Kota Jambi - Singapura kala itu. Selain itu pembangunan Bandara Sultan Thaha Syaifuddin (STS) Jambi juga terus dilakukan. Impian Zulkifli Nurdin membangun Bandara Sultan Thaha Syaifuddin (STS) Kota Jambi menjadi bandara bertaraf internasional akhirnya terwujud ketika anaknya, Zumi Zola menjadzadi Gubernur Jambi 2016 - 2017 (Saragih, 2018).

\section{Dominasi Keluarga Zulkifli Nurdin di Partai Amanat Nasional}

Pertama, Dominasi keluarga Nurdin mulai terlihat ketika adiknya Hazrin Nurdin terpilih secara aklamasi sebagai Ketua DPW PAN Provinsi Jambi dalam Musyawarah DPW PAN Provinsi Jambi ke-4. Hatta Rajasa yang juga turut hadir dan kepada peserta musyawarah bahwa Zulkifli Nurdin sebagai mantan Ketua DPW PAN Provinsi Jambi, hanya bergeser ke samping, Zulkifli Nurdin akan tetap berjuang untuk PAN, dari pernyataan tersebut menggambarkan bahwa betapa pentingnya sosok Zulkifli Nurdin bagi PAN di Jambi, tentu penunjukan adik nya sebagai ketua DPW menunjukan Zulkifli menggunakan PAN sebagai alat untuk membangun dinasti politiknya, tidak ada 
produksi pemimpin PAN diluar keluarga dan kroninya.

Kedua, terpilihnya Ratu Munawaroh Zulkifli menjadi DPR RI, dengan meraih suara terbanyak dalam pemilihan anggota DPR RI daerah pemilihan Provinsi Jambi tahun 2009. Berdasarkan penelusuran data Ratu Munawaroh Zulkifli berhasil meraih suara sebesar 157.651 suara pemilih dari total 1.333 .626 pemilih yang menjadi rekor nasional, Selain Ratu Munawaroh Zulkifli, terpilih juga salah satu orang dekat Zulkifli Nurdin, Haji Bakri. Haji Bakri mendapat 18.954 suara pemilih, Ini tentu menunjukan besarnya pengaruh Zulkifli Nurdin sebagai suami dari Ratu Munawaroh, dan juga sebagai Gubernur Jambi yang masih menjabat mobilisasi pemilih dari Pegawai Negeri tentu pasti terjadi (Arnoldi, 2019). Ratu Munawaroh merupakan istri kedua Zulkifli Nurdin yang mendampingi Zulkifli dari awal kepemimpinan menjadi Gubernur hingga selesai, Ratu Munawaroh sendiri banyak terlihat didalam acara pemerintahan sehingga dia dapat menarik partisipasi para aparatur sipil dalam memilihnya sebagai anggota DPR RI dengan suara terbanyak pada tahun 2009 (Burhani, 2018).

Tabel 1.2. Rekapitulasi Suara Pemilihan DPR RI 2009

\begin{tabular}{llll}
\hline No & Nama Calon Terpilih & Nama Partai & Suara Sah \\
\hline 1. & Ratu Munawaroh Zulkifli & PAN & 157.651 \\
\hline 2. & Dr. Indrawati Sukadis & Partai Demokrat & 53.008 \\
\hline 3. & H. Irsal Yunus, SE, MM & PDI Perjuangan & 43.007 \\
\hline 4. & Drs. H. A. Murady Darmansyah & Partai Hanura & 39.224 \\
\hline 5. & Selina Gita, SE & Partai Golkar & 38.262 \\
\hline 6. & Drs. H. Asad Syam, MM & Partai Demokrat & 22.827 \\
\hline 7. & H.A. Bakri HM, SE & PAN & 18.954 \\
\hline
\end{tabular}

Sumber : kpu.go.id

Ketiga, Peran Zulkifli Nurdin dalam membantu Zumi Zola maju pada Pemilihan Gubernur Jambi tahun 2015. Zumi Zola yang merupakan anak Zulkifli Nurdin yang saat itu menjabat menjadi Bupati Tanjung Jabung Timur, kurang dari setahun lagi Zumi Zola menyelesaikan tugasnya menjadi seorang bupati, Zumi memutuskan untuk mengundurkan diri. Zumi mencalonkan diri sebagai Gubernur Jambi mengikuti jejak sang ayah yang sukses memimpin Jambi selama dua periode yakni 1999-2004 dan 2005-2010.

Pada saat itu memiliki kompetitor yang juga sebagai pertahana yaitu Hasan Basri Agus yang sudah menyelesaikan periode pertamanya menjadi Gubernur Jambi akan bersaing melawan Zumi Zola pada pilgub tahun 2015. Kuatnya peran keluarga 
Zulkifli Nurdin dan dominasi di PAN ternyata memberikan langkah Zumi Zola menuju Gubernur Jambi pun terbilang mulus. Berdasarkan hasil penghitungan suara, Zumi dan pasangannya Fachrori Umar sukses mendulang banyak sura mencapai 60,2 persen. Zumi Zola dan Fachrori Umar pun dilantik menjadi Gubernur dan Wakil Gubernur Jambi pada 12 Februari 2016 di Istana Negara. Sejak saat itu, Zumi resmi menjadi orang nomor satu di Jambi (Ariefana, 2019).

Tabel 1.3. Rekapitulasi Suara Pilkada Jambi 2015

1. Hasan Basri Agus dan Edi Purwanto (Biru)

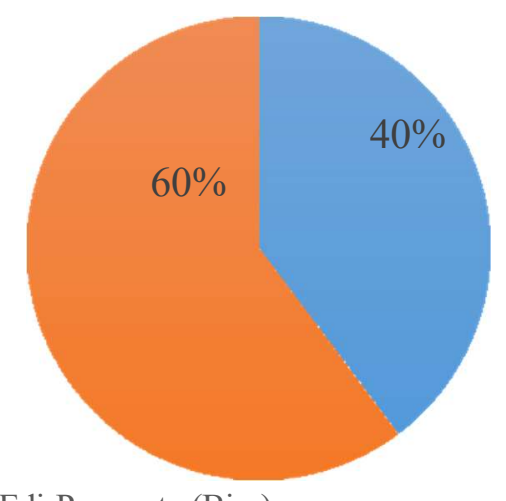

2. Zumi Zola Zulkifli dan Fachrori Umar (Orange)

\section{Sumber : kpu.go.id}

Keempat, terpilihnya Zumi Laza menjadi ketua DPD PAN Kota Jambi, dalam musda yang dilakukan bulan febuari 2016 di hotel Wiltop. Pemilihan Zumi Laza tentu tidak terlepas dari dominasi keluarga dan peran Zulkifli Nurdin, Zumi Laza sendiri merupakan adik dari Zumi Zola yang saat itu menjabat menjadi Gubernur Jambi. Bayangan publik terkait dengan PAN dijadikan sebagai alat oleh Zulkifli Nurdin untuk membangun dinasti politik semakin terlihat kenyataanya dengan menempatkan anakanaknya di posisi strategis untuk meneruskan dominasinya (Cas, 2016).

\section{KESIMPULAN}

Berbagai daerah di Indonesia pasca runtuhnya Orde Baru telah melahirkan problematika baru yaitu munculnya local strongman. Salah satunya berlangsung di Jambi pada masa desentralisasi. Local strongman yang dahulu merupakan golongan elit yang dibesarkan secara ekonomi dan politik oleh Orde Baru yang dahulu merupakan bekas dari "Golongan Karya" dan mempunyai akses terhadap sumber daya ekonomi di tingkat lokal karena merupakan kumpulan pengusaha.

Zulkifli Nurdin merupakan orang kuat lokal di Jambi era desentralisasi, Zulkifli 
Nurdin merupakan keturunan langsung dari pengusaha terkaya di Jambi, Nurdin Hamzah. Nurdin Hamzah tidak saja mewarisi kekayaan kepada Zulkifli Nurdin tetapi juga dengan basis politik yang kuat di Tanjung Jabung Timur. Zulkifli Nurdin berhasil membangun citra diri yang dermawan, merakyat dan reformis, pada akhirnya dapat mencapai titik kejayaan dalam dominasinya di Provinsi Jambi, citra baik dan dominasi keluarga beserta kroninya mampu membuahkan hasil dari mulai perjalanan Zulkifli ke politik, menjadi ketua PAN hingga Gubernur Jambi dua periode, serta peran nya yang mendominasi di PAN dari menjadikan adiknya Hazrin Nurdin sebagai ketua DPW PAN, lalu peranya menaikan elektabilitas istrinya Ratu Munawaroh hingga duduk di DPR RI dan juga peran Zulkifli dalam memenangkan anaknya Zumi Zola di Pemilihan Gubernur Jambi tahun 2015, hingga menjadikan adiknya Zumi Zola yaitu Zumi Laza menjadi ketua DPD PAN Kota Jambi tahun 2015.

\section{DAFTAR PUSTAKA}

Agustino, L. (2016). Politik Lokal Di Indonesia : Dari Otokratik Ke Reformasi Politik. In Jurnal AIPI (Vol. 27, Issue 6).

Holifah, N. (2012). Kekuatan Local Strongman dalam Pilkada Sampang 2012. 66, 3739.

Melvin, Perjuangan, H. (2012). Fenomena "Orang Kuat Lokal" Di Indonesia Era Desentralisasi (Studi Kasus Tentang Dinamika Kekuasaan Zulkifli Nurdin Di Jambi). In FISIP UI.

Migdal, J. S. (2004). State in Society: Studying How States and Societies Transform and Constitute One Another. 1-7.

Sidel, J. T. (2000). Capital, coercion, and crime: bossism in the Philippines. Choice Reviews Online, 38(04), 38-2396-38-2396.

Creswell John W., 2010, Research Design : Qualitative, Quantitative, and Mixed Methods Approaches, 3th, terjemahan Achmad Fawaid, Yogyakarta

Ketek, Naik. (2018, Febuari 4). Zulkifli Nurdin, Zumi Zola dan politik dinasti di Jambi. Kumparan. Diakses dari http://www.kumparan.com.

Rachmawan, Deddy. (2018, November 30). Kisah Almarhum Zulkifli Nurdin, Umur 5 Tahun Hatam Al-Quran \& Pernah Jadi Pedagang Tepung \& Gula. Tribun Jambi. Diakses dari https://jambi.tribunnews.com.

Ariefana, Pebriansyah. (2019, Febuari 13). Perjalanan Karier Zumi Zola, From Hero to Zero Karena Korupsi. Suaracom. Diakses dari https://suara.com.

Cas. (2016, Febuari 24). Terpilih di Musda PAN Kota Jambi, ini komentar Zumi Laza. Jambi Update. Diakses dari https://www.jambiupdate.co.

Saragih, Radesman. (2018, November 29). In Memoriam Zulkifli Nurdin Gubernur yang Getol Membangun. Berita Satu. Diakses dari https://www.beritasatu.com.

Arnoldy, Andika. (2019, April 30). Cek fakta : Ibu Tiri Zumi Zola Ratu Munawarah Raih Suara Terbanyak Pemilu 2009 Capai 150 Ribu Suara. Tribun Jambi. Diakses dari https:// www.tribunnews.com.

Apriyani, Tia. (2020, Maret 31). Kebijakan Desentralisasi Hanya Menjadi Arena Nyaman Bagi Elit Politik. Suaracom. Diakses dari https://suara.com. 
Burhani, Hanif. (2020, November 30). Mengenal Ratu Munawaroh, Ibu Tiri Zumi Zola yang Setia Mendampingi Hingga Zulkifli Nurdin Berpulang. Tribun Jambi. Diakses dari https://tribunnews.com

\section{Website}

(http://www.kpu.go.id) 